\title{
Investigating the relationship between job involvement and intention to leave job in anesthetist employed in Sanandaj hospitals in 2018
}

\author{
Kamel abdi $^{1}$, Mokhtar yaghobi ${ }^{2}$, Arvin barjanji ${ }^{3}$, Shilan ghaderi ${ }^{4}$, Daem $_{\text {roshani }}{ }^{5}$, Aram karimian $^{6}$ \\ 1. Instructor, Nursing department, faculty of medicine, Komar University of science and technology, Sulaymaniya, Kurdistan \\ region, Iraq. ORCID ID: 0000-0001-8896-0038 \\ 2. Instructor, Clinical Care Research Center, Kurdistan University of Medical Sciences, Sanandaj, Iran. ORCID ID: 0000- \\ 0002-3131-2010 \\ 3. Instructor, Department of Anesthesiology, School of Paramedical Sciences, Kurdistan University of Medical Sciences, \\ Sanandaj, Iran. ORCID ID: 0000-0003-0680-5128 \\ 4. Instructor, Department of Emergency Medical Sciences, School of Paramedical Sciences, Kurdistan University of Medical \\ Sciences, Sanandaj, Iran. ORCID ID: 0000-0003-4339-6095 \\ 5. Associate Professor, Social Determinants of Health research Center, Research Institute for Health Development, Kurdistan \\ University of Medical Sciences, Sanandaj, Iran. ORCID ID: 0000-0003-4746-1114 \\ 6. Instructor, Social Determinants of Health research Center, Research Institute for Health Development, Kurdistan \\ University of Medical Sciences, Sanandaj, Iran. Tel: 08733664645 Email: ar.bio67@ gmail.com. ORCID ID: 0000-0001- \\ $8705-325 x$
}

\begin{abstract}
Background and Aim: job involvement and intention to leave job are important feedbacks of work. The purpose of this study was to investigate the relationship between job involvement and intention to leave job among anesthetist employed in Sanandaj hospitals in 2017.

Material and Methods: In this descriptive-analytical study, 90 anesthetist working in Sanandaj hospitals were enrolled in the study. Data were collected from the Kanongo Job Anxiety Questionnaire, Attwod and Hinshaw Vacancy Forecasting Questionnaire and demographic and occupational information questionnaire. Version 23 of SPSS software was used for data analysis. Data were analyzed using descriptive statistics, independent t-test and chi-square test.
\end{abstract}

Results: The mean and standard deviation of job involvement and intention to leave job were $2 \pm 0.056$ and $2 \pm 0.063$, respectively. Also, the results showed that there is a significant relationship between job involvement and intention to leave job with all demographic and occupational variables $(\mathrm{p}<0.05)$.

Conclusion: Considering the low level of job involvement and the high intention to leave job in anesthetist, rooting and planning is recommended by the authorities.

Key words: Job Involvement, Intention to Leave, Anesthesia, Hospital

Received: May 21, 2019

Accepted: Jan 19, 2020

How to cite the article: Kamel abdi, Mokhtar yaghobi, Arvin barjanji, Shilan ghaderi, Daem roshani, Aram karimian. Investigating the relationship between job involvement and intention to leave job in anesthetist employed in Sanandaj hospitals in 2018. SJKU. 2020; 25(1):84-92.

Copyright (C) 2018 the Author (s). Published by Kurdistan University of Medical Sciences. This is an open access article distributed under the terms of the Creative Commons Attribution-Non Commercial License 4.0 CBYNC), where it is permissible to download, share, remix, transform, and buildup the work provided it is properly cited. The work cannot be used commercially without permission from the journal 


\title{
بررسى رابطهى دلبستكى شغلى با تمايل به ترك خدمت دركار كنان هوشبرى شاغل در بيمارستان هاى شهر سندج در سال
}

\author{
كامل عبدى'، مختار يعقوبى'، آروين برزنجى"، شيلان قادرى'، دائم روشنى'، آرام كريميان'

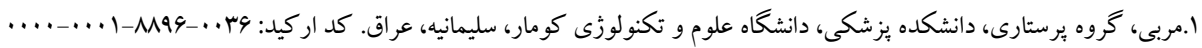

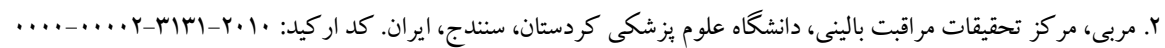

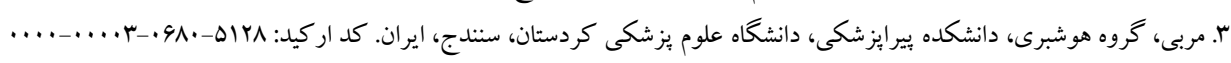

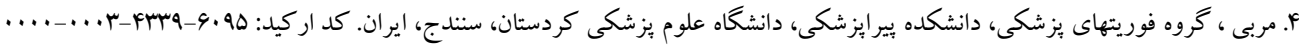

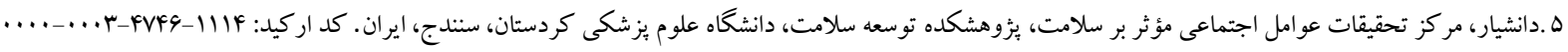

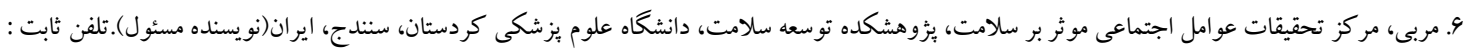

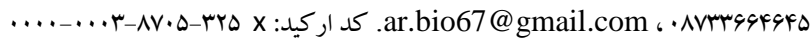

جكيuه

زمينه و هدف: سازمهاى دلبستگى شغلى و تمايل به تركى خدمت از بازخوردهاى مهم مرتبط با كار مىباشند. اين مطالعه با

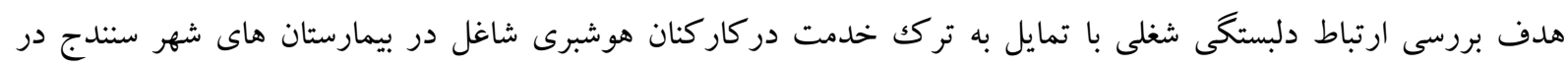

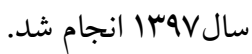
مواد و روشها: در اين مطالعه توصيفى-تحليلى ، تعداد •و نفر از كاركنان هوشبرى شاغل در بيمارستانهاى شهر سنندج به

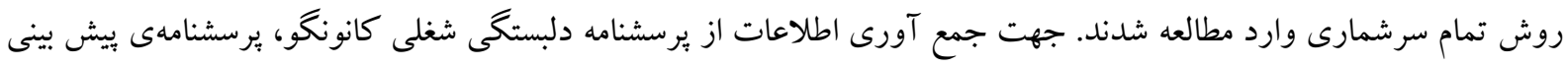

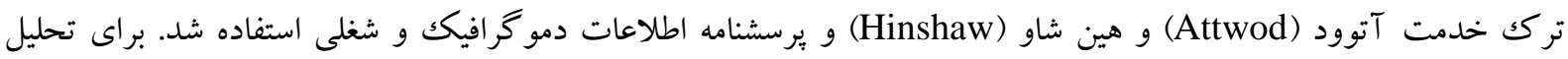

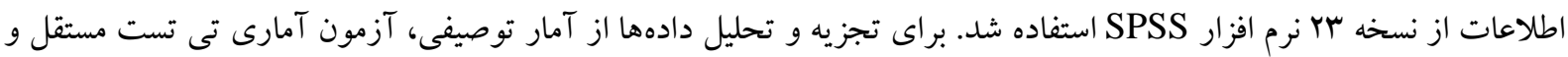

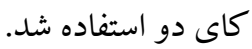

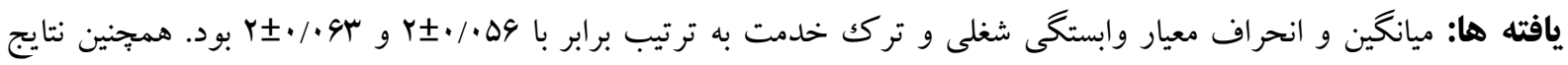

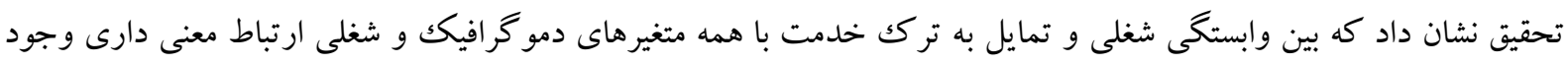

دارد) نتيجه كيرى: با توجه به يايين بودن دركيرى شغلى و بالا بودن تمايل به ترك خدمت درد در كار كنان هوشبرى بيمارستانهاى شهر

$$
\begin{aligned}
& \text { سنتدج، ريشه يابى و برنامهريزى دقيق از سوى مدير بهان مربوطه دراين زمينه بيشنهاد مى بشوده. }
\end{aligned}
$$

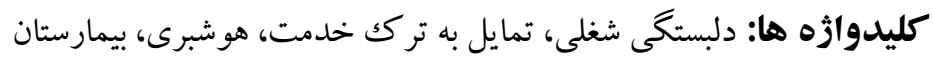

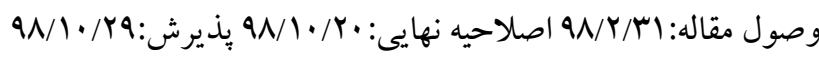


زندگى فردى و كارى رادر كار كنان به دنبال داشته باشد .

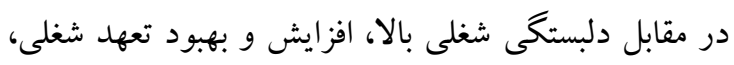
رضايت شغلى، افزايش بهره ورى، كاهش غيبت از كار و افزايش حس سازمانى را به دنبال خواهد داشت(r). از طرف له ديخر تمايل به ترك خدمت نيز انديشه و قصد فرد نسبت به رابه دبه تركك خدمت مىباشد، اگرجه فرد در حال حاضر در موقعيت شغلى خود مانده باشد. ميل به تركك خدمت فرد مترادف ترك خدمت بيش بينى شده است كه به معنى احتمال ترك موقعيت شغلى توسط فرد مى باشد(بال).

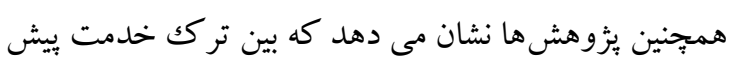

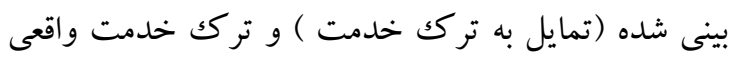

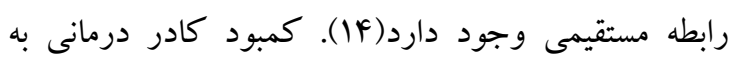
دنبال تركك حرفه، خود بر كيفيت مراقبت ارائه شده تأثير به داديه

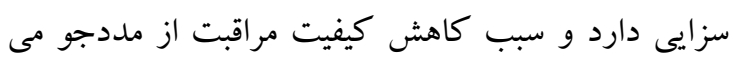

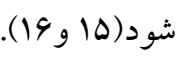
در ميان شاغلان در بخش هاى درمانى مختلف، كاركنان

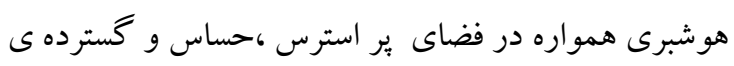
حرفه ى خود با جالش هاى حرفه اي ويزه دست و ينجه نرم

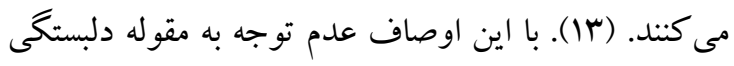
شغلى و تركك خدمت ناشى از آن در كار كنان هوشبرى مى آنى تواند آسيب هاى متعددى به كل نظام سلامت وارد كند. از

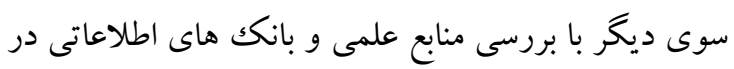

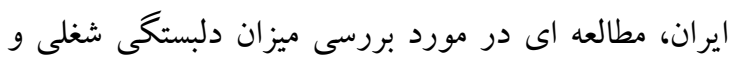

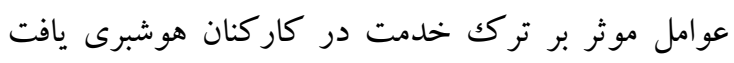

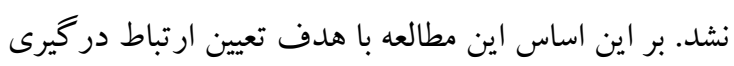

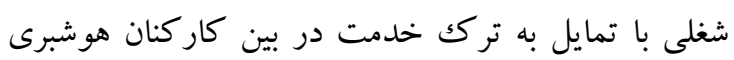
شاغل در بيمارستان هاى شهر سندج در سال Vوسا انجام

\section{مواد و روشها}

اين مطالعه توصيفى- تحليلى مى باشد كه با هدف تعيين

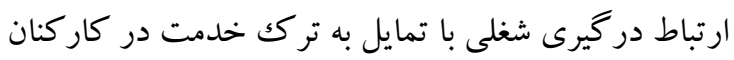
هوشبرى شاغل در بيمارستان هاى شهر سنندج انجام شد.

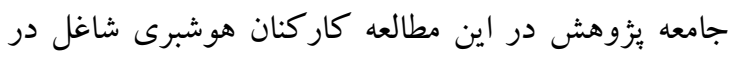

مقدمه

سازههاى دلبستگى شغلى و تمايل به تركى خدمت از

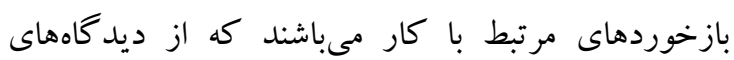

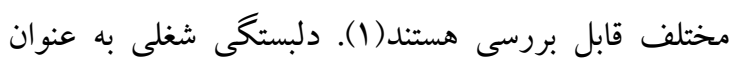
اشتياق، رضايت و احساس شور و شعف در محيط كار تعريف شده است به گونه اي كه موجب مى شود كار كنان

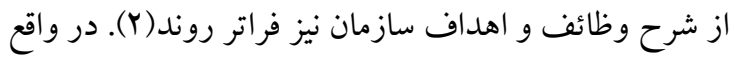

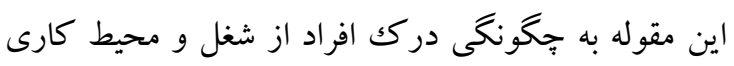
خود و هماهنكى بين شرايط شغلى و زندكى شخصى آنها

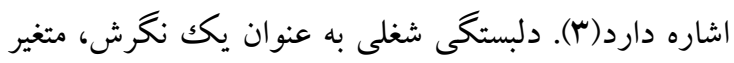

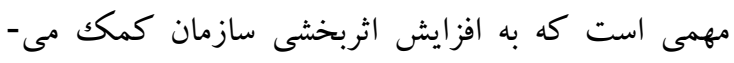

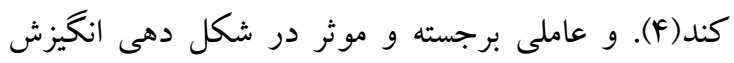

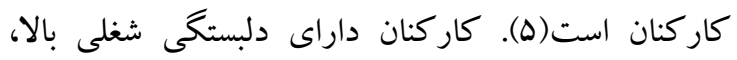

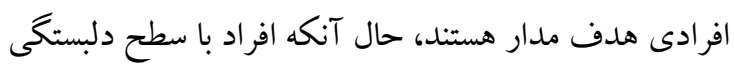
شغلى بايين افرادى با ويز گى ترس شديد از شكست هستند.

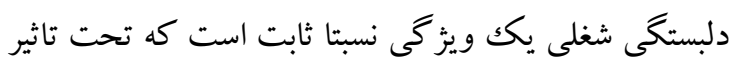

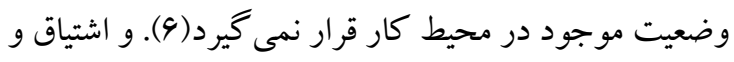

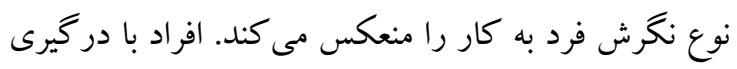

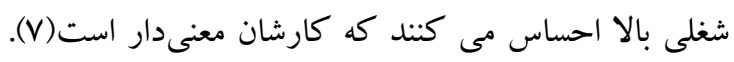

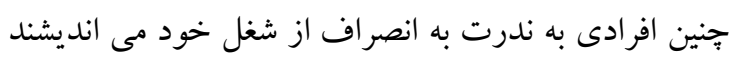

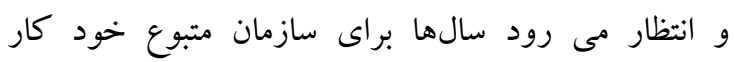
كنند(A). دلبستكى شغلى درجه ايست كه فرد در كار خود

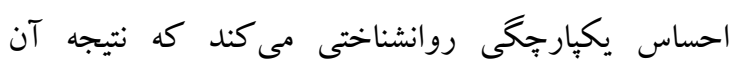

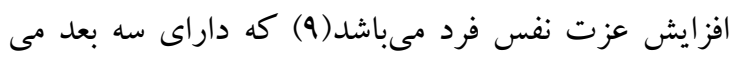

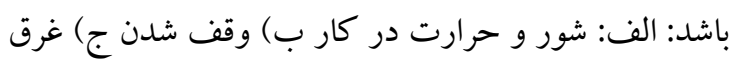

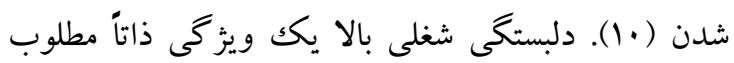

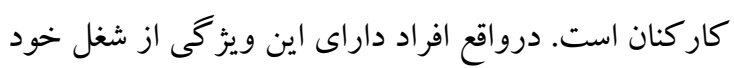

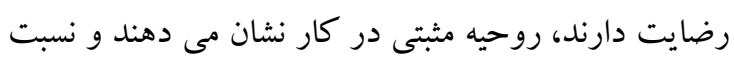
به سازمان و همكاران خود تعهد بالايى ابراز مى كنند (11).

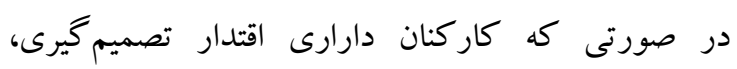
مسئوليتيذيرى و سرعت عمل در كار را داشته باشند،

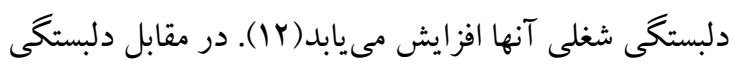

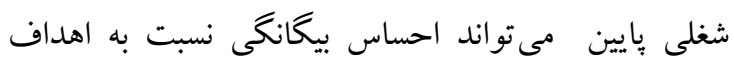

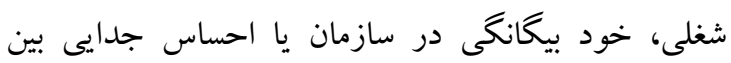


نرم افزار SPSS نسخه سץ استفاده شد. براى تجزيه و تحليل دادهها از آمار توصيفى، براى مقايسه ميانخينها از آزمون

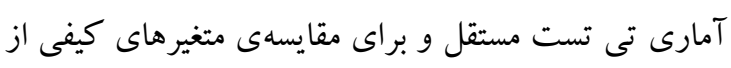
كاى دو استفاده شد.

يافته ها

براساس نتايج اين يزوهش كه برروى •9 يرسشنامه تكميل

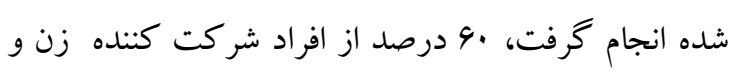

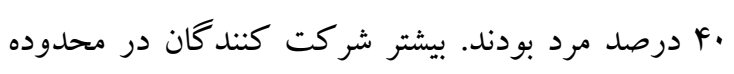

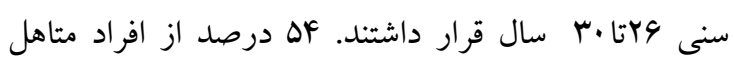
بودند. از نظر سابقه كار بالينى بيشتر افراد شركت كنتده داراى سابقه كار كمتر از ه سال بودند( وسادرصد). از ميان

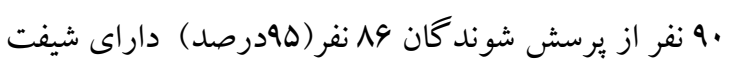
كارى جرخشى بودند(جدول ال).

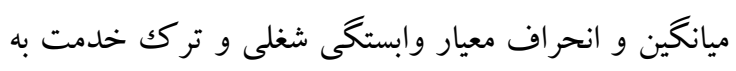

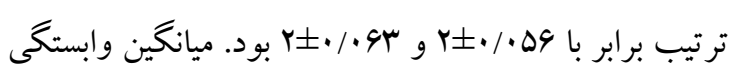

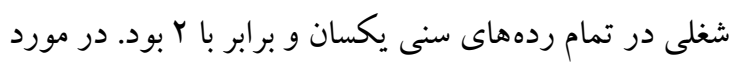

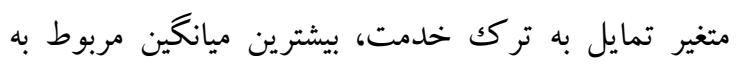

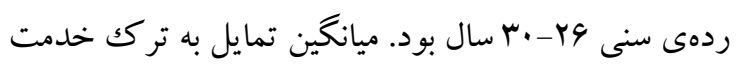

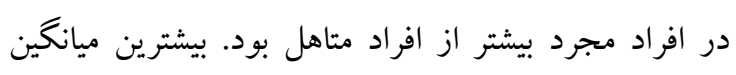

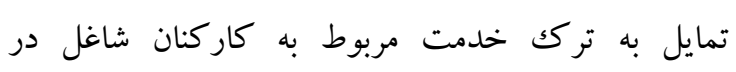
بيمارستان هاى غيردولتى بود. همجينين نتايج تحقيق نشان داد

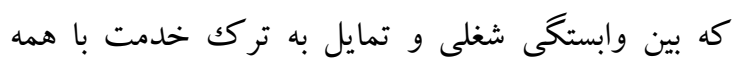

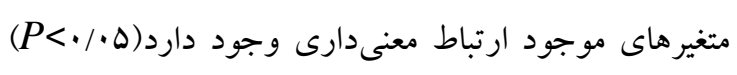

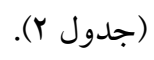

بيمارستان هاى شهر سندج بودند كه به صورت تمام شمارى وارد مطالعه شدند. معيار هاى ورود به مطالعه شامل دارا بودن حداقل يكسال سابقه كار و دارا بودن حداقل

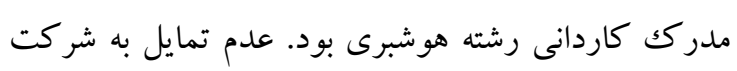
در مطالعه و عدم تكميل كامل برسشنامه ها به عنوان معيار خروج در نظر كرفته شد. جهت جمع اورى اطلاعات از

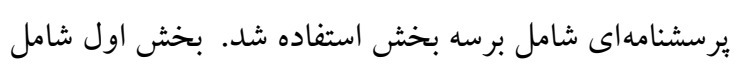

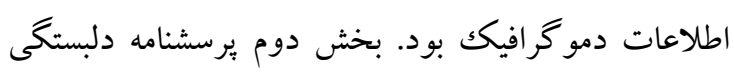

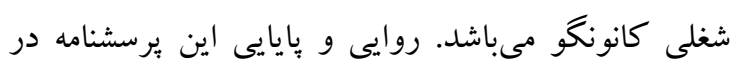

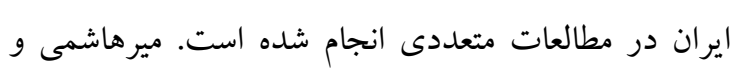

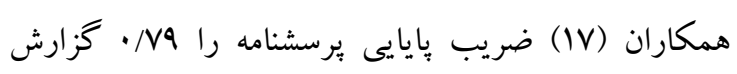

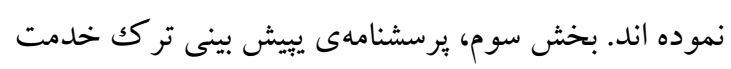

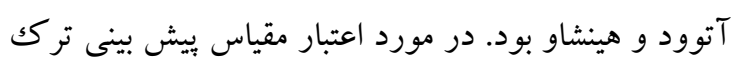

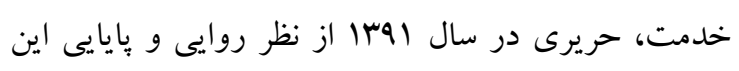
مقياس را به تأييد رسانده است. شاخص اعتبار محتواى ساى الهال

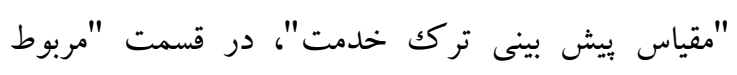

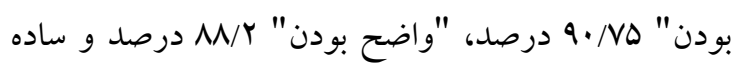
بودن MN/FI درصد بود و همبستخى درونى"مقياس ييش

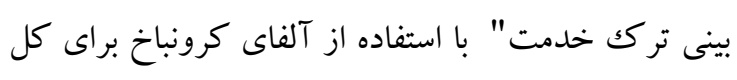

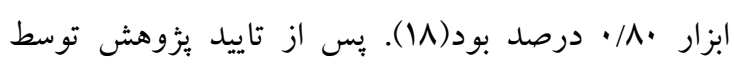

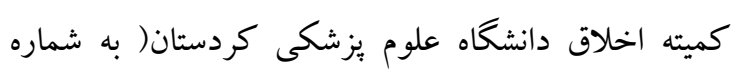

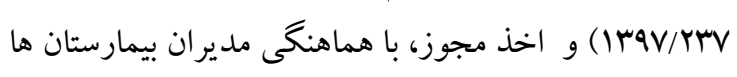

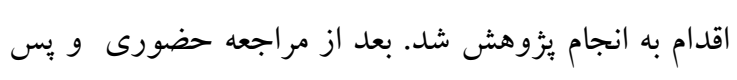
از توضيح اهداف بزوهش و كسب رضايت كتبى آكاهانه و اطمينان در حفط محرمانه بودن اطلاعات، برسشنامهها توزيع شد. در اين يزوهش، براى تحليل اطلاعات جمع آورى شداز 
جدول ا: فراوانى افراد شر كت كننده برحسب متغير هاى دمو كر افيك و شغلى

\begin{tabular}{|c|c|c|c|}
\hline درصد & تعداد & \multicolumn{2}{|c|}{ متغير هاى دمو كر افيك و شغلى } \\
\hline rr & r. & $r \cdot-r \Delta$ & \\
\hline rr & rq & rG-r. & سن \\
\hline r & rI & هוr & \\
\hline rr & $r$. & $r \Delta<$ & \\
\hline 4. & $\Delta F$ & زن ان & جنس \\
\hline f. & rq & مرد & \\
\hline FD & Fi & مجرد & وضعيت تاهل \\
\hline$\Delta F$ & Fq & متاهل & \\
\hline f. & rq & $\Delta>$ & \\
\hline ro & rr & $9-1$. & سابقه خدمت \\
\hline r. & 11 & $11-10$ & \\
\hline If & ir & $10<$ & \\
\hline 90 & $\wedge 9$ & جرخى & شيفت كارى \\
\hline$\Delta$ & F & ثابت & \\
\hline 11 & r & 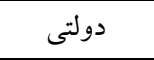 & \\
\hline 19 & iv & غير دولتى & 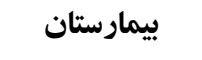 \\
\hline$r F$ & M & زير ليسانس & سطح تحصيلات \\
\hline 90 & $\Delta q$ & بالاى ليسانس & \\
\hline
\end{tabular}

جدول r: متغير هاى دموكر افيك و شغلى، آزمون هاى آمارى و سطح منى دارى متغيرها

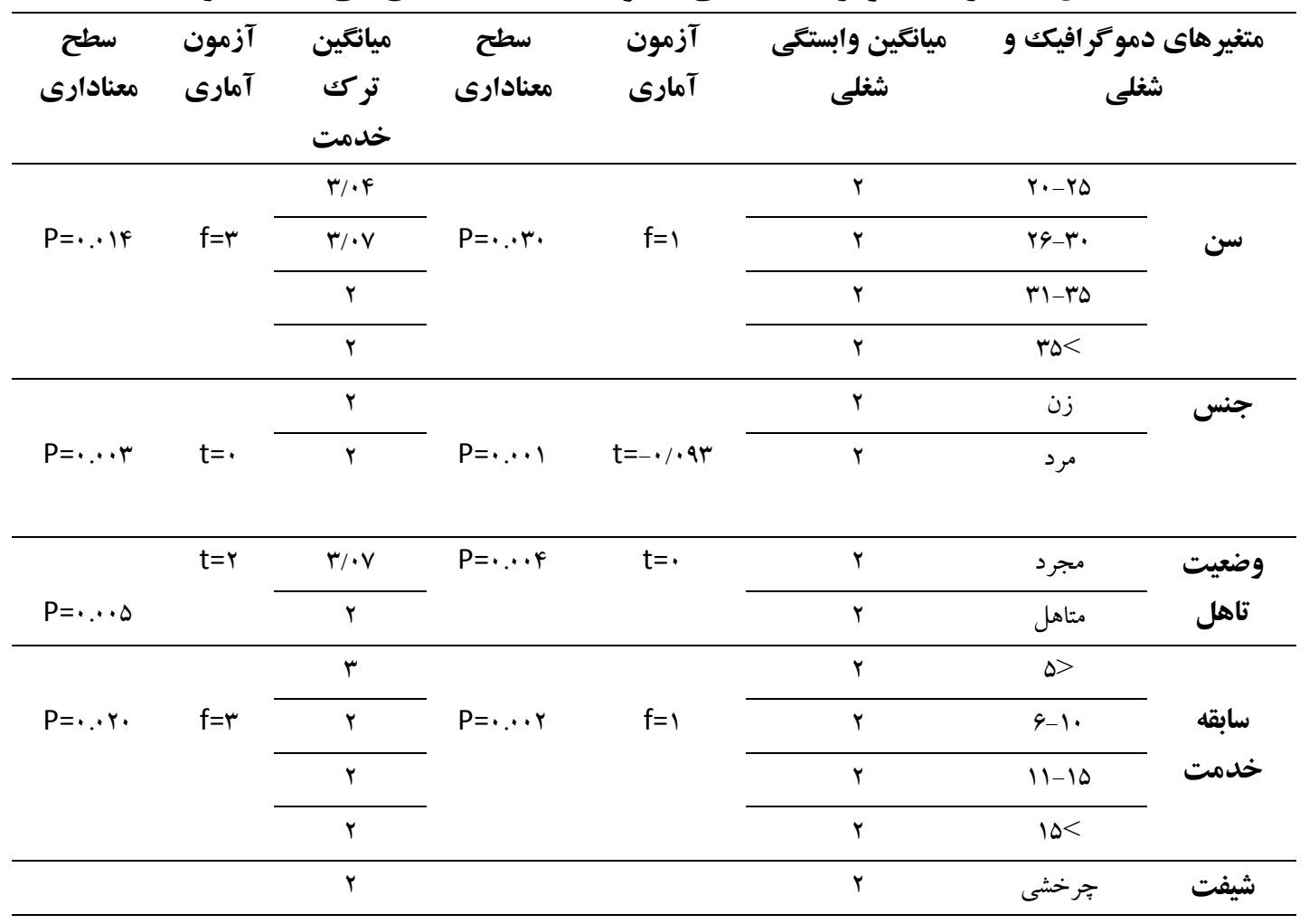




\begin{tabular}{|c|c|c|c|c|c|c|c|}
\hline$P=. . \cdot 1$ & $t=$ & $r$ & $P=. .1$ & $t=$ & $r$ & ثابت & كارى \\
\hline & & r & & & $r$ & دولتى & \\
\hline \multirow[t]{4}{*}{$P=. . .1 r$} & $f=r$ & & $P=. . . r$ & $f=r$ & & & بيمارستان \\
\hline & & $r$ & & & r & غير دولتى & \\
\hline & & & & & & & خدمت \\
\hline & & $r$ & & & r & زير ليسانس & سطح \\
\hline$P=. . .4$ & $t=-r$ & $r$ & $P=. . .1$ & $t=r$ & $r$ & بالاى ليسانس & تحصيلات \\
\hline
\end{tabular}

همجنين نتايج يُزوهش نشان مىدهد كه بين جنس و

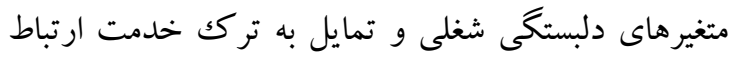

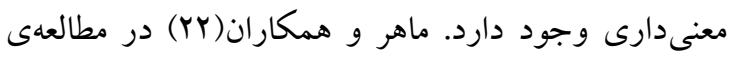
خود كه با هدف بررسى تاثير دلبستكى شغلى روى تمايل به وديه

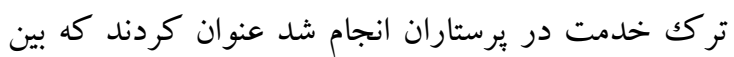
جنس و تمايل به تركك خدمت و دلبستكى شغلى ارتباط معنى دارى وجود ندارد كه با نتايج اين مطالعه ناهمسو بود اما

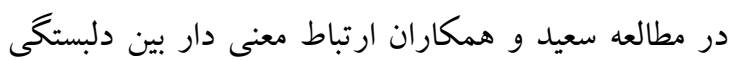

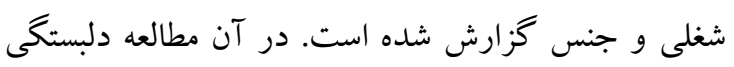
شغلى در كاركنان مرد بيشتر از زن مىباشد كه دلايل آن اشتغال بيشتر مردان و اشتغال به كار مردان در سمت هاى شغلى بالاتر بيان شده است. از نظر وضعيت تاهل نيز براساس نتايج جدول شمارهب

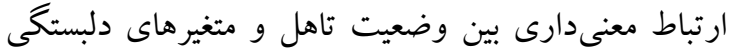
شغلى و تمايل به تركك خدمت وجود دارد. همجنين نتايج مطالعه نشان مىدهد افراد مجرد تمايل بيشترى به تركك خدمت نسبت به كاركنان متاهل دارند كه با توجه به مسئوليتهاى خانوادگى كمتر و وابستخى كم اين افراد به حقوق و مزاياى دريافتى اين موضوع قابل انظار مى باشد. در مطالعهى كولس (Kols) وهمكاران (19) نيز كه با هدف

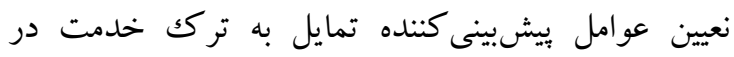
كاركنان هوشبرى كشور اتيويى انجام شد، افراد مجرد

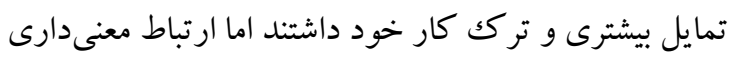

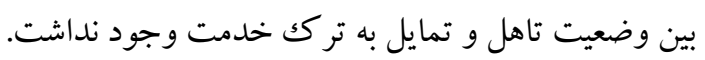

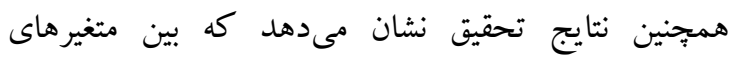
دلبستكى شغلى و تمايل به تركى خدمت با سابقه كارى نئن

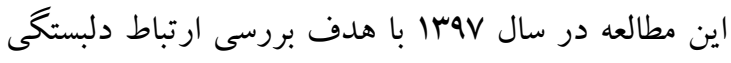
شغلى و تمايل به تركك خدمت در كاركنان هوشبرى شاغل در بيمارستان هاى شهر سنندج انجام شد. براساس نتايج جدول شماره rا، بين سن و متغيرهاى دلبستخى شغلى و تمايل به تركك خدمت ارتباط معنى دارى وجود دارد. ميانخين دلبستكى شغلى در ردههاى سنى مختلف يكسان بود اما

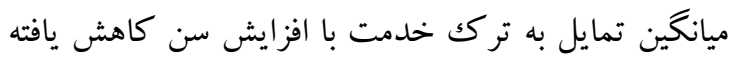

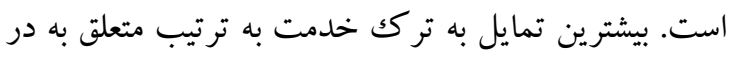

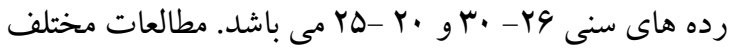
نيز نشان مىدهند بين سن و تمايل به ترك خدمت رابطه

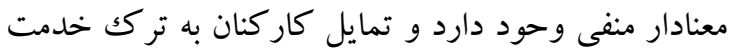
با افزايش سن كاهش مىيابد(IV)(IV). كاركنان با سن ״ايين، احتمالا وابستخى مالى كمترى دارند و بيشتر به ادامه تحصيل و تغيير رشته و ارتقاى آن فكر مى كنند، حال انكه با افزايش سن، وابستخى مالى و مشكلات خانوادگى بيشتر شده و تمايل به ادامه تحصيل نيز كاهش مىيابد. اما در زمينه ى دلبستكى شغلى در مطالعه ى سعيد وهمكاران(ب) بين سن

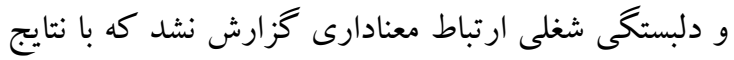
اين مطالعه همسو نبود. هر جند مطالعات مختلف عنوان مى كنند كه افزايش سن توام با افزايش فرسودگى و خستخى شغلى مىباشد(·r و اYr) و اين عوامل خود باعث كاهش دلبستخى شغلى مى شوند اما شواهدى از همبستخى بين سن و و إنى دلبستخيى شغلى موجود نيست. در اين مطالعه نيز با افزايش سن، ميانگين دلبستخيى شغلى تغييرى نداتشه است. 
9. براسى (ابطه دلبستكى شغلى...

آموزشى و غير آموزشى از نظر متغيرهاى دلبستكى شغلى و تمايل به ترك خدمت مشاهده نشد.

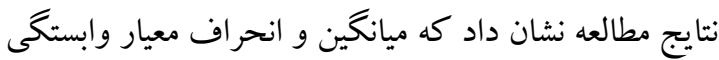
شغلى و تمايل به ترك خدمت به ترتيب برابر با وهـ/•Y

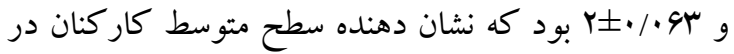
هر دو متغير مى باشد. قادرى و همكاران (rT) نيز در مطالعه خود تمايل به ترك خدمت را در برستاران شاغل در استان كردستان در سطح متوسط ارزيابى كردند. در اين مطالعه تامين نيروهاى بيشتر و كارآمد جهت كاهش بار بار كارى

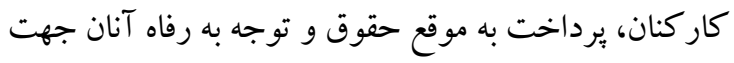
كاهش تمايل به ترك خدمت كاركنان اشاره شده است.

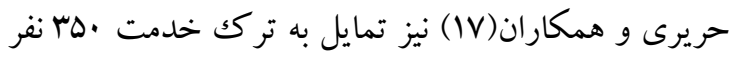

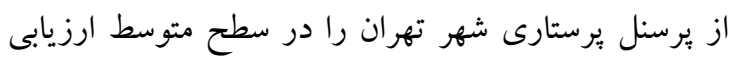
كردند كه با نتايج اين مطالعه همسو بود. در مطالعه حريرى تهري

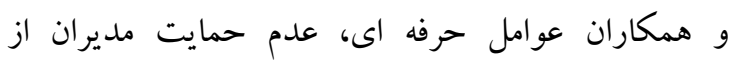
كار كنان، كافى نبودن حقوق و مزايا و عدم تامين نيازهاى

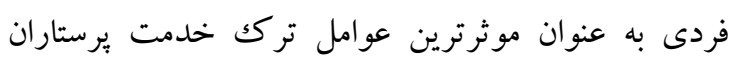
ذكر شده است. كولس و همكاران (19) نيز در مطالعه خود بيان كردند كه

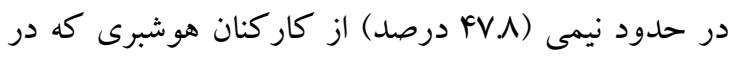

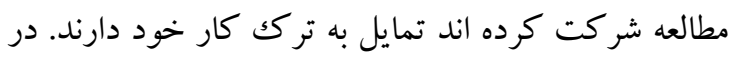

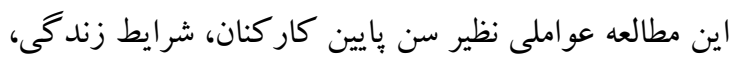

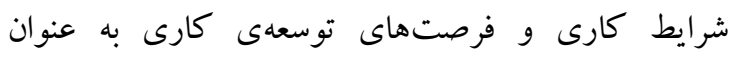
مهمترين عوامل موثر در تمايل به ترك خدمت وند كاركنان

$$
\text { هوشبرى ذكر شده است. }
$$

در اين مطالعه ميزان دلبستخى شغلى كار كنان نيز در سطح متوسط قرار دارد كه با مطالعه ى سعيد و همكاران(r) كه با لـاني هدف بررسى دلبستكى شغلى و عوامل دمو گر افيك مرتبط با آن در يرستاران انجام شده بود، همسو مى باشد. سعيد و

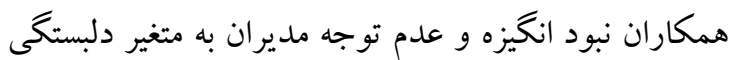
شغلى را از عوامل تاثير كذار در اين زمينه بيان كرده اند. يكى از محدوديتهاى مطالعه حاضر، عدم بررسى ويثز

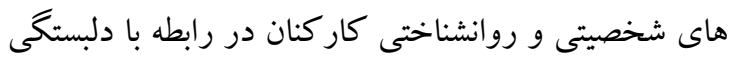

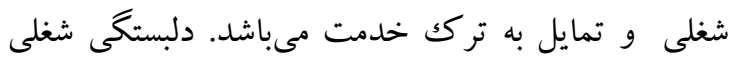

رابطه معنىدارى وجود دارد و ميانگين تمايل به تركك خدمت با افزايش سابقهى كارى كاهش مىيابد. در اين

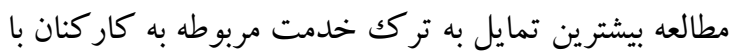
سابقهى كارى كمتر از هـ سال مىباشد. با توجه به اينكه افراد با سابقه كارى كمتر، سن كمترى داشته و عمدتا مجرد هستند، اين موضوع منطقى به نظر مىرسد. همرجنين نتايج اين بخش از مطالعه با مطالعه ميرهاشمى و همكاران(1)

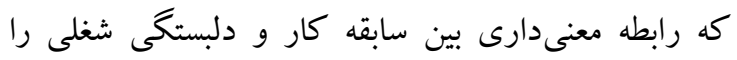
كزارش كرده بود همسو بود. در مطالعه ميرهاشمى عنوان

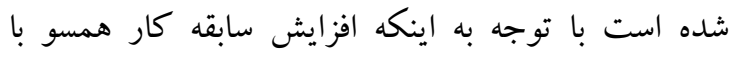

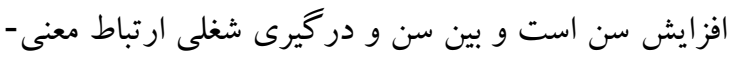

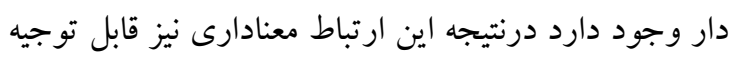

در مورد سطح تحصيلات، نتايج مطالعه ارتباط معنادارى بين

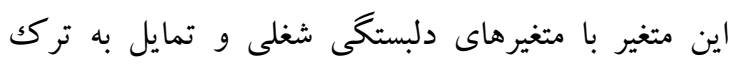

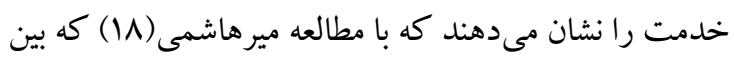
مدرك تحصيلى و دلبستخى شغلى ارتباط معنى دارى يافت نشد؛ همسويى نداشت. همجِنين در اين مطالعه ميزان تمايل

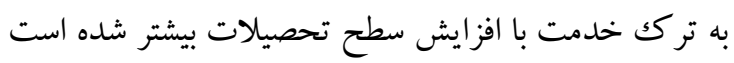
كه دليل اين موضوع را مىتوان بايين بودن سطح توقعات

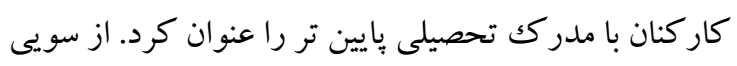
ديخر بالا رفتن سطح تحصيلات باعث مى شود كه كار كنان

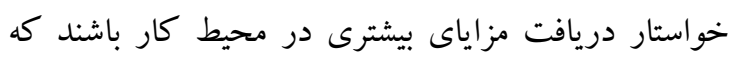

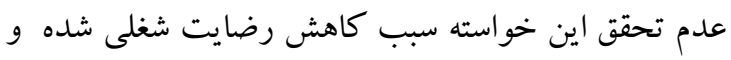
به تبع آن درگيرى شغلى كاهش مى يابن.

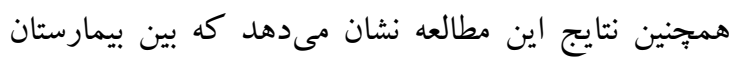

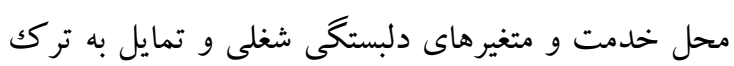
خدمت ارتباط معنى دار وجود دارد. در اين مطالعه كاركنان شاغل در بيمارستان هاى غير دولتى تمايل به ترك خدمت بيشترى دارند. شايد دليل آن را بتوان بار كارى بيشتر، حقوق لقال

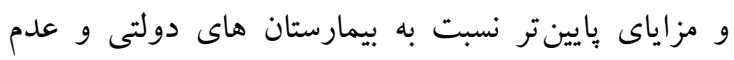
امنيت شغلى بيان كرد هرجند مطالعهاى مشابه در جهت تاييد اين موضوع يافت نشد. تفاوتى بين بيمارستانهاى دولتى 


$$
\begin{aligned}
& \text { بودن نخرش مثبت به شغل و بايين بودن تعهد نسبت به كار و }
\end{aligned}
$$

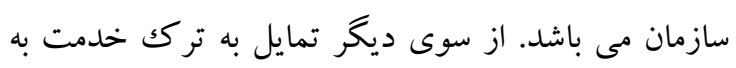

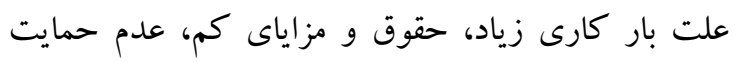

$$
\begin{aligned}
& \text { مديران و ساعات كارى زياد، بالا مى باشد. اين وضعيت نياز }
\end{aligned}
$$

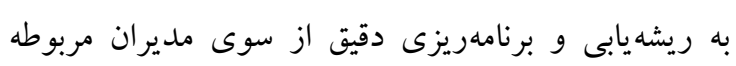

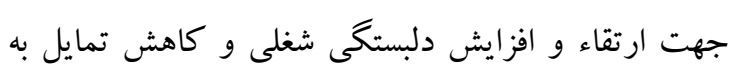

$$
\begin{aligned}
& \text { ترك خدمت دارد. }
\end{aligned}
$$

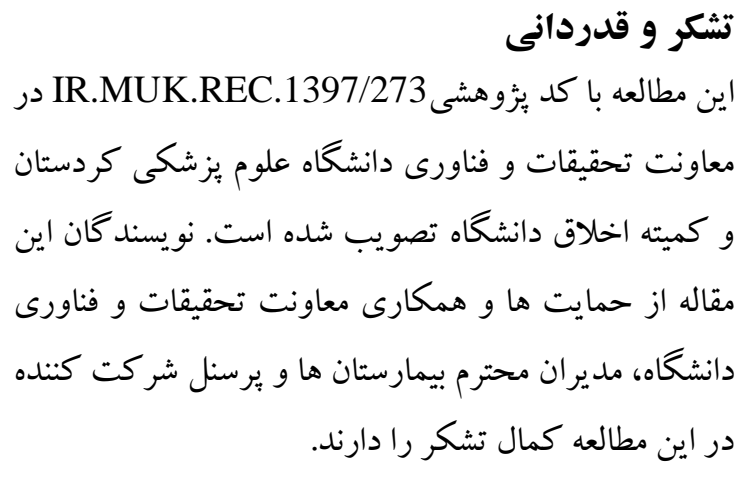$$
\text { تشكر و قدردانى }
$$

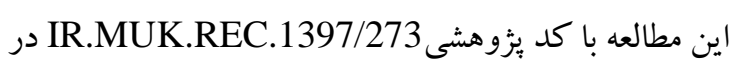
معاونت تحقيقات و فناورى دانشكاه علوم بزشكى كردستان و كميته اخلاق دانشگاه تصويب شده است. نويسند كان اين

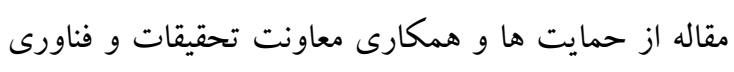

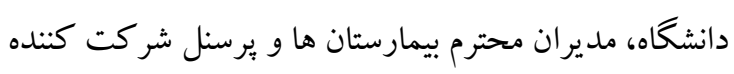
در اين مطالعه كمال تشكر را دارند.

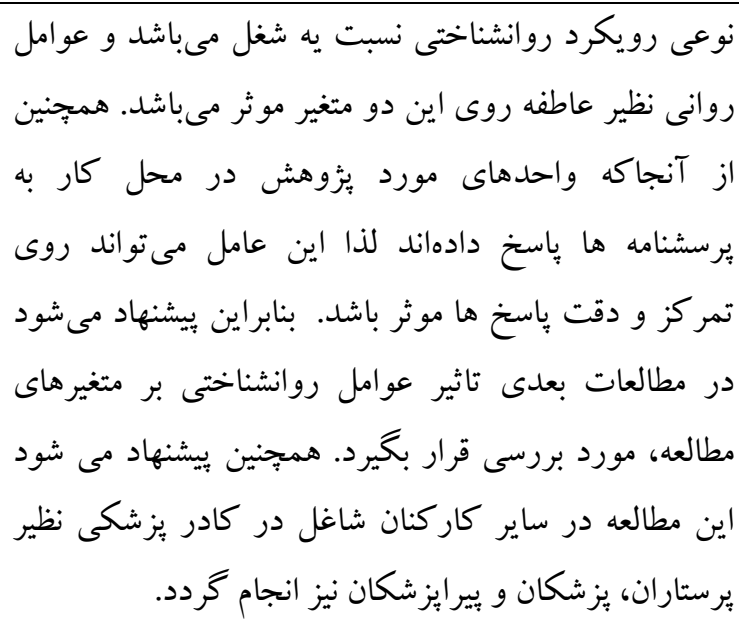

منابع

1.Moafimadani SM, Teymourzadeh V. Study of Relationship between Emotional Intelligence and Job Involvement in Future Management. J Manag Syst. 2015;23(4):65-74.

2.Shahmohammadi A, Ardalan MR, Zandi K, Seifpanahi H, Feizi K. Relationship between Spiritual Leadership and Job Engagement: A Case Study of Kurdistan University Employees. J Hum Resour Manag. 2015;5(17):135-56.

3.Yaser S, Tabanejad Z, Nahrir B, Ebadi A, Khoshab H, Babajani S. The relationship between job involvement and demographic characteristics in nurses in hospitals of Tehran and Kerman in 2013. J Clin Nurs Midwifery. 2014;3(4):39-46.

4.Ziaei M, Rezaei G, Yarmohammadi H, khoshboo E, Gharagozlou F. The relationship between teachers' job involvement and demographic characteristics in Dalahou (Kermanshah) secondary schools in 2013. J Ergon. 2015; 3 (1) :59-64.

5.Mirhashemi M, Hanafi K. The relationship between entrepreneurship and job involvement among staff of Islamic Azad University Roudehen ranch. Mod Thoughts Educ. 2012;7(1):4158.

6.Karimzadeh Z. Predicting Job Involvement of IAU Faculty Members based on their Philosophical Mind-Set (A Case Study in Roudehen Branch of IAU). J Mod Thoughts Educ. 2013;8(2):82-92.

7.Wang M-L, Chang S-C. The Impact of Job Involvement on Emotional Labor to CustomerOriented Behavior: An Empirical Study of Hospital Nurses. J Nurs Res. 2016;24(2):153-62.

8.Khalesi N, Salehi M, Moradi F, Ahadinezhad B, Mohammadi R, Rohani B. The Relationship between Servant Leadership and Job Involvement of staff in Teaching Hospitals

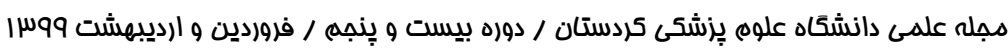


9p براسى (ابطم دلبستكى شغلى...

Affiliated to Kurdistan University of Medical Sciences: 2011. J Heal Adm. 2012;15(47):2332.

9.Song J, Lee N, young Park S. The Influence of Verbal Aggression on Job Involvement and Turnover Intention in Organizational System. IJASC . 2015;4(2):54-60.

10.Zardoshtiyan S, Abbasi H, Esmaeili M, Khanmoradi S. The Relationship Perceived Organizational Support, Job Involvement and Organizational Citizenship Behavior of Physical Education Teachers in Hamedan Province. Organ Behav Manag Sport Stud. 2015;2(6):93-103.

11.Kalantari M, ghorchian N, sharifi HP, Jafari P. A model to promote managers' job involvement in islamic azad universities based on cognitive styles, locus of control, and leadership styles. J Mod Thoughts Educ. 2011;6(2):123-40.

12.Ravangard R, Mohamadi Z, Sajjadnia Z, Ghanavatinejad Z. Nurses' Job Involvement and Their Personality Traits in Teaching Hospitals Affiliated to Shiraz University of Medical Sciences, 2013. Heal Sco. 2014;3(1):1-5.

13.Volk MC, Lucas MD. Relationship of management style and anticipated turnover. Dimensions of critical care nursing: DCCN. 1991;10(1):35-40.

14.Lucas MD, Atwood JR, Hagaman R. Replication and validation of anticipated turnover model for urban registered nurses. J Nurs Res. 1993;42(1):29-35

15.Burmeister EA, Kalisch BJ, Xie B, Doumit MA, Lee E, Ferraresion A, Terzioglu F, Bragadóttir $\mathrm{H}$. Determinants of nurse absenteeism and intent to leave: an international study. J nurs manag. 2019;27(1):143-53.

16.Corley MC, Minick P, Elswick RK, Jacobs M. Nurse moral distress and ethical work environment. Nurs eth. 2005;12(4):381-90.

17.Mirhashemi M, Pashasharifi H, Sabeti S. The relationship between emotional intelligenceand job involvement in nurses. Idea \& Behavior. 2007; 3(9): 17-26.

18.Hariri GR, Yaghmaei F, Zagheri Tafreshi M, Shakeri N. Assessment of some factors related to leave in nurses and their demographic charater in educational hospitals of Shahid Behesthi University of Medical Sciences. JHPM. 2012;1(3):17-27

19.Kols A, Kibwana S, Molla Y, Ayalew F, Teshome M, van Roosmalen J, Stekelenburg J. Factors Predicting Ethiopian Anesthetists' Intention to Leave Their Job. World J Surg. 2018;42(5):1262-69.

20. Kagwe J, Jones S, Johnson SL. Factors Related to Intention to Leave and Job Satisfaction among Registered Nurses at a Large Psychiatric Hospital. Issu in ment heal nurs. 2019 ;40(9):754-9.

21.Rahimnia F, Sadeghian S, Yazdani P. The Moderating Role of Self-esteem between Burnout and Social Undermining in the Nurses of Charity Hospitals in Mashhad. Iran $\mathrm{J}$ of Nurs. 2017 ;30(109):67-79.

22.Maher A, Sotoudeh H, Hosseini SM. Effect of Job-Involvement on Job-Burnout of Nurses Working in Lahijan'Seyed Al-Shohada Hospital. IRJM. 2016;3(2):27-34.

23.Ghaderi S, Rezagholy P, Tawana H, Nuri B. The Relationship between Occupational Burnout and Intention to Leave in Nurses Working in Training Hospitals in Sanandaj, Iran. SJNMP. 2019;4(3):25-34. 